(REVIEW ARTICLE)

\title{
Use of drugs in children with impaired liver function
}

\author{
Muzal Kadim* \\ Gastrohepatology Division, Child Health Department University of Indonesia, Ciptomangunkusomo Hospital.
}

Publication history: Received on 03 December 2020; revised on 12 December 2020; accepted on 14 December 2020

Article DOI: https://doi.org/10.30574/wjarr.2020.8.3.0475

\begin{abstract}
Liver disorders in children will affect the pharmacokinetics and pharmacodynamics of drugs that are metabolized in the liver. Chronic liver disease in children such as chronic hepatitis, cirrhosis of the liver can affect the absorption and disposition (pharmacokinetics) of drugs and the efficacy and safety (pharmacodynamics) of drugs in the body. Dosage modification is determined based on clinical studies examining the effects of impaired liver function on the pharmacodynamics and pharmacokinetics of a drug.
\end{abstract}

Keywords: Chronic liver disease; Children; Drug dose adjustment

\section{Introduction}

Metabolism and elimination of drugs in our body can be carried out in various ways and is carried out by various organs, including the liver, intestinal walls, kidneys, blood plasma. The most important organ in this process is the liver [1,2]. Liver disease that can cause liver dysfunction can be categorized into two, namely acute liver disease (acute viral hepatitis, autoimmune hepatitis, metabolic disorders, etc.) and chronic liver disease (chronic hepatitis, fatty liver, cholestasis, and others) [3-7]. Chronic liver disease in children such as chronic hepatitis, cirrhosis of the liver can affect the absorption and disposition (pharmacokinetics) of drugs and the efficacy and safety (pharmacodynamics) of drugs in the body. This article aims to discuss drug use, including drug dosage adjustments in children with liver dysfunction.

\section{Hepatic drug clearance}

The etiology of different liver disorders will give different patterns in causing liver dysfunction. Cirrhosis, for example, will increase hepatic vascular resistance, reduce liver blood flow, which can lead to hepatic portal-systemic shunting and changes in the liver sinusoids [1]. The number and activity of hepatocytes is also reduced, such as cytochrome $\mathrm{P}$ 450 activity, reduced albumin production, all of which can interfere with drug metabolism in the body. Hepatic drug clearance is affected by both hepatic blood flow and liver enzyme function. The liver extraction rate is defined as the percentage of drug removed from the blood in one flow to the liver [8.9]. High clearance drugs mean that these drugs are metabolized primarily in the liver (high hepatic extraction ratio), so that the metabolic process and elimination of these drugs are strongly influenced by hepatic drug clearance. In contrast to low clearance drugs, drug metabolism and elimination are not completely dependent on the liver. As liver function decreases, there will be changes in blood flow and liver enzyme activity, thereby reducing hepatic drug clearance, which will affect drugs with intermediate and high hepatic extraction ratios. This condition will increase the concentration of circulating and non-binding drugs in the blood. $[8,9]$.

\footnotetext{
${ }^{*}$ Corresponding author: Muzal Kadim

Gastrohepatology Division, Child Health Department University of Indonesia, Ciptomangunkusomo Hospital. 


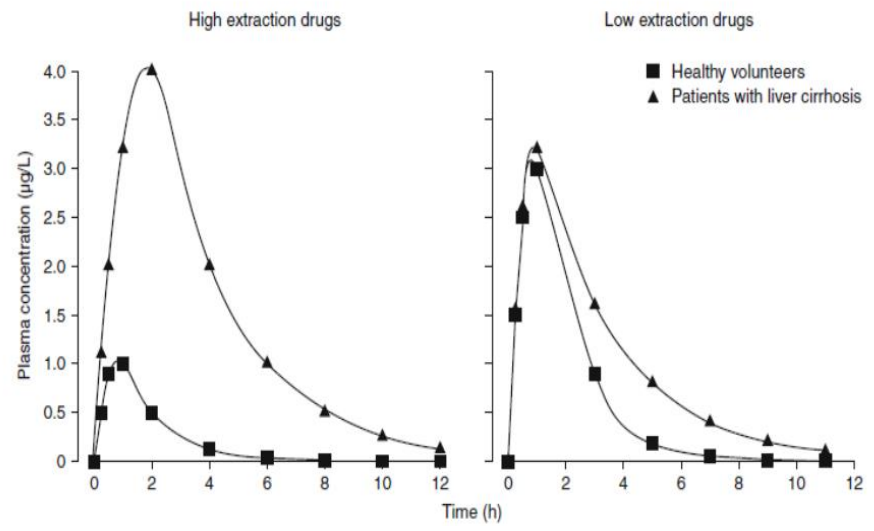

Figure 1 Relationship of liver cirrhosis to drug pharmacokinetics [10]

\section{Drug use and dosage modification}

To date, no universal marker has been found to predict drug elimination in the body. The Child-Pugh classification is often used, although the original aim of this classification was to predict one- and two-year survival in patients with impaired liver function.

Table 1 Child-Pugh classification for degree of hepatic dysfunction [11].

\begin{tabular}{|l|l|l|l|}
\hline \multirow{2}{*}{ Parameter } & \multicolumn{2}{|l|}{ Score } & $\mathbf{3}$ \\
\cline { 2 - 4 } & $\mathbf{1}$ & $\mathbf{2}$ & $\mathbf{3}$ \\
\hline Ascites & None & Mild to moderate & Severe \\
\hline Bilirubin (mg/dL) & $\leq 2$ & 2 to 3 & $>3$ \\
\hline Albumin (g/dL) & $>3,5$ & 2,8 to 3,5 & $<2,8$ \\
\hline Prothrombin Time & & & \\
\hline Second above normal & $1-3$ & $4-6$ & $>6$ \\
\hline INR & $<1,7$ & 1,8 to 2,3 & $>2,3$ \\
\hline Encephalopathy & None & $\begin{array}{l}\text { Grade } 1-2 \\
\text { Mild to moderate }\end{array}$ & $\begin{array}{l}\text { Grade } 3-4 \\
\text { Severe }\end{array}$ \\
\hline
\end{tabular}

The total score of 5-6 is grade A (mild, well-compensated disease); 7-9 is grade B (Moderate, significant functional compromise); and 10-15 are grade C (Severe, decompensated disease). Grading is associated with one and two year survival: grade A $100 \%$ and $65 \%$, grade B $80 \%$ and $60 \%$, grade C $45 \%$ and $35 \%$.

Guidelines have been published by the Food and Drug Administration (FDA) and the European Medicines Agency (EMEA) [12,13], to determine the adjustment of drug doses in children with decreased liver function. These guidelines recommend the Child-Pugh classification for assessing the severity of liver disorders. For mild hepatic impairment and liver function that is well compensated for, grade A in the Child-Plugh classification, no adjustment of drug doses is necessary. Changes in drug doses are generally made in patients with grade B (Moderate) and grade C (Severe) according to the Child-Pugh classification.

Dosage modification is determined based on clinical studies examining the effects of impaired liver function on the pharmacodynamics and pharmacokinetics of a drug. The drug is then labeled to show the difference in the effect of the drug when given to patients with impaired liver function such as [12] : 
- This drug makes no difference when used in patients with decreased liver function.

- This drug makes a difference when used in patients with decreased liver function (dose modification is necessary / this drug is contraindicated / or may be used with extreme caution).

If there are no clinical studies regarding the use of a drug in patients with impaired liver function, the following labels should be printed:

- The liver does not contribute to the elimination of this drug.

- Limited drug elimination occurs in the liver $(<20 \%)$

- Wide drug elimination occurs in the liver $(>20 \%)$

Additional labels are provided for drugs with a wide or narrow therapeutic range. Alternatively, if there are no studies that provide information on dosage adjustments for a drug, drug dosage changes can be made according to the recommendations made by Periane-Parraga et al as shown in table 2 [14].

Table 2 Categories and dosage recommendations in patients with impaired liver function.

\begin{tabular}{|l|l|l|l|l|}
\hline Category & $\mathbf{E}_{\mathbf{H}}$ & $\mathbf{F}$ & PB & Recommendations \\
\hline 1 & High ( $\geq 60 \%)$ & $\leq 40 \%$ & Any & $\begin{array}{l}\text { Reduction in Id and Md with the } \\
\text { reduction dose formula = (Nd x F) / } \\
100\end{array}$ \\
\hline 2 & Intermediate (30-60\%) & $40-70 \%$ & Any & $\begin{array}{l}\text { Id: Starting in the low range of normal } \\
\text { doses } \\
\text { Md: Must be adjusted as in Low EH and } \\
\text { Low PB }\end{array}$ \\
\hline 3 & Low $\leq 30 \%)$ & $\geq 70 \%$ & $\geq 90 \%$ & $\begin{array}{l}\text { Drug monitoring } \\
\text { Md: } \\
\text { CP A: } 50 \% \text { dari Nd } \\
\text { CP B: } 25 \% \text { dari Nd } \\
\text { CP C: drug monitoring }\end{array}$ \\
\hline 4 & Unknown & & & \\
\hline
\end{tabular}

Id: Initial dose. Md: Maintenance dose. Nd: Normal dose without hepatic impairment. EH: Hepatic extraction ratio. F: Bioavailability. PB: Fraction bounds to proteins. CP: Child-Pugh Index

The first step that needs to be done is to categorize the drugs into three:

- Hepatic extraction ratio (EH) - High $\geq 60 \%$, Intermediate $30-60 \%$, and low $\leq 30 \%$

- Bioavailability (F)

Plasma protein binding (PB)

Recommendations for administration and adjustment of drug doses can be made base on the table above.

\section{Use of drugs in children with decreased liver function}

Various types of drugs are affected by decreased liver function. Macrolide class antibiotics such as erythromycin, azithromycin should be avoided. Propofol and opiate sedatives (fentanyl) are more frequently used than the benzodiazepines. Analgesics must be given with caution because of the side effects and complications that are more severe. Nonsteroidal anti-inflammatory agents (NSAIDs) are contraindicated because of complications of 
gastrointestinal tract bleeding. Paracetamol is a safe alternative at doses less than 2 grams/day. Anticonvulsants such as phenytoin, carbamazepine, and valproic acid are hepatotoxic and should therefore be given at lower doses.

Antihypertensive drugs such as captopril, labetolol, also require close monitoring because of their hepatotoxic effects. The statin dyslipidemia drug is safe for use in patients with cirrhosis. Types of drugs commonly used in children and recommended dosage adjustments are listed in table 3 [10].

Table 3 Types of drugs and recommended dosage adjustments in patients with liver cirrhosis.

\begin{tabular}{|c|c|}
\hline High hepatic extraction $(\geq 60 \%)$ & Dosage adjustment recommendations \\
\hline $\begin{array}{l}\text { Morphine, pentazocine, propoxyphene, } \\
\text { venlafaxine, promethazine, fluvastatin, lovastatin, } \\
\text { sumatriptan, ciclosporin, fluorouracil, idarubicin, } \\
\text { mercaptopurine, sirolimus, tacrolimus, } \\
\text { vinorelbine, bromocriptine, levodopa, selegiline, } \\
\text { biperiden, chlorpromazine, chlorprothixene, } \\
\text { flupentixol, quetiapine, propranolol, nicardipine, } \\
\text { verapamil, buspirone, midazolam }\end{array}$ & $\begin{array}{l}\text { Reduce the initial dose and maintenance of oral } \\
\text { administration } \\
\text { Reduce the maintenance dose according to the } \\
\text { information on the drug label or the estimated } \\
\text { hepatic clearance } \\
\text { Must be extra careful with drugs with a low } \\
\text { therapeutic index }\end{array}$ \\
\hline Intermediate hepatic extraction (30-60\%) & Dosage adjustment recommendations \\
\hline $\begin{array}{l}\text { Codeine, pethidine, amiodarone, lidocaine, } \\
\text { amitriptyline, clomipramine, mitrazapine, } \\
\text { nortriptyline, paroxetine, intraconazole, } \\
\text { atorvastatin, simvastatin, entacapone, clozapine, } \\
\text { haloperidol, olanzapine, omeprazole, ranitidine, } \\
\text { diltiazem, nifedipine. }\end{array}$ & $\begin{array}{l}\text { Initation of administration at a low dose. } \\
\text { Adjusting the maintenance dose depending on the } \\
\text { classification of Child-Pugh class A ( } 50 \% \text { normal } \\
\text { dose), B ( } 25 \% \text { normal dose), or C (use a safe drug, not } \\
\text { affected by hepatic function). }\end{array}$ \\
\hline $\begin{array}{l}\text { Low hepatic extraction }(\leq 30 \%) \text { and low protein } \\
\text { binding }(\leq 90 \%)\end{array}$ & Dosage adjustment recommendations \\
\hline $\begin{array}{l}\text { Paracetamol, doxycycline, } \\
\text { fluoxetine, metoclopramide, } \\
\text { phenobarbital, carbamazepine, } \\
\text { bromazepam, risperidone, } \\
\text { methylprednisone, prednisone, isoniazid }\end{array}$ & $\begin{array}{l}\text { Initiation of administration at normal dose } \\
\text { Adjusting the maintenance dose according to the } \\
\text { intermediate hepatic extraction drug. }\end{array}$ \\
\hline $\begin{array}{l}\text { Low hepatic extraction and high protein binding } \\
(>90 \%)\end{array}$ & Dosage adjustment recommendations \\
\hline $\begin{array}{l}\text { Clindamycin, phenytoin, valproic acid, } \\
\text { lansoprazole, diazepam, lorazepam, prednisolone, } \\
\text { rifampicin. }\end{array}$ & $\begin{array}{l}\text { To guide drug administration in cirrhotic patients } \\
\text { with hypoalbuminemia it is necessary to estimate the } \\
\text { concentration of the free drug in the blood }\end{array}$ \\
\hline
\end{tabular}

\section{Conclusion}

Liver disorders in children will affect the pharmacokinetics and pharmacodynamics of drugs that are metabolized in the liver. To date, no tests or clinical trials have been found that can accurately determine the relationship between liver function and drug dose adjustment. Drug dose adjustments are based on clinical studies of patients with decreased liver function. If a drug type study is not found, the pharmaceutical company should provide information on the hepatic extraction ratio, bioavailability and plasma protein binding. The dose adjustment can then be made by determining the degree of liver damage using the Child-Pugh classification, and the information listed above. In the future, more research is needed on the pharmacokinetics and pharmacodynamics of drugs commonly used in children with liver disorders, and reliable tests to guide dose adjustment. 


\section{Compliance with ethical standards}

\section{Acknowledgments}

We would like to acknowledge the support provided by the Department of Child Health, Faculty of Medicine, University of Indonesia, for the realisation of this article.

\section{Disclosure of conflict of interest}

The authors have no conflicts of interest to declare.

\section{References}

[1] Verbeeck R. Pharmacokinetics and dosage adjustment in patients with hepatic dysfunction.European Journal of Clinical Pharmacology. 2008; 64: 1147-61.

[2] Stirnimann G, Reichen J. Drug prescription in liver disease, in Textbook of clinical gastroenterology and hepatology. Second ed. Hawkey C J BJ, Ritcher G, Garcia-Tsao, Chan F K L., editor. Oxford, UK: Wiley-blackwell; 2012.

[3] Ibrahim A, Ali M, Ghanem H, et al. Simple and rapid detection of liver cirrhosis in children by tracking serum IgA/ transferrin ratio. Journal of experimental and integrative medicine. 2011; (2): 117-21.

[4] Squires R. Acute liver failure in children. Seminars in Liver Disease. 2008; 28(2): 153-66.

[5] Papandreou D RI, Mavromichalis I. . Update on non-alcoholic fatty liver disease in children. Clinical Nutrition. 2007; 26: 409-15.

[6] Anil D. Etiology and prognosis of acute liver failure in children. Liver transplantation. 2008; 14(Supplementation 2): $S 80-4$.

[7] Feldstein AE, Charatcharoenwitthaya P, Treeprasertsuk S, Et al. The natural history of non-alcoholic fatty liver disease in children: a follow-up study for up to 20 years. GUT. 2009; 58: 1538-44.

[8] Dourakis SP. Drug therapy in liver diseases. Annals of Gastroenterology. 2008; 21(4): 215-7.

[9] Tandon RK. Prescribing in patients with liver disease. Medicine Update. 2012; 22: 494-7.

[10] Dose adjustment of drugs with high hepatic extraction are required in patients with severe liver disease. Drugs Ther Perspect. 2006; 22(5): 23-6.

[11] Pugh R, Murray-Lyon I, Pietroni M, Williams R. Transection of the oesophagus for bleeding oesophageal varices. Br J Surg. 1973; 60: 646-9.

[12] FDA. Guidance for industry: pharmacokinetics in patients with impaired hepatic function: study design, data analysis, and impact on dosing and labelling. 2003.

[13] EMEA. Guideline on the evaluation of the parmacokinetics of medicinal products in patients with impaired hepatic function. 2005.

[14] Perianez-Parraga L, Martinez-Lopez I, Ventayol-Bosch P, Puigventos-Latorre F, Delgado-Sanchez O. Drug dosage reccomendations in patients with chronic liver disease. Rev Esp Enferm Dig. 2012; 104(4): 165-84. 